\title{
Design and Testing of Piezoelectric Energy Harvesting Devices for Generation of Higher Electric Power for Wireless Sensor Networks
}

\author{
*Meiling Zhu, Member, IEEE and Emma Worthington \\ Department of Materials \\ Cranfield University \\ Bedfordshire, UK \\ *Email: $\underline{\text { m.zhu@cranfield.ac.uk }}$
}

\begin{abstract}
This paper reports our design and testing results on the electric output performance of a vibration-based piezoelectric energy harvesting device (PEHD). The PEHD is a cantilever with a sandwich structure and seismic mass attached to the tip. The geometric parameters of the device are based on optimization design with a volume of around $1 \mathrm{~cm}^{3}$ and at a targeted resonant frequency of 80-100 $\mathrm{Hz}$. A maximum output power of $370 \mu \mathrm{W}$ at 15.5 volts into a $325 \mathrm{k} \Omega$ resistive load is generated at the resonant frequency of $87 \mathrm{~Hz}$ and under an acceleration of $\mathbf{0 . 2 3 g}$. Quite remarkably, this power is a very encouraging power figure that gives the prospect of being able to power a wider range of applications than is currently possible in wireless sensor network.
\end{abstract}

\section{INTRODUCTION}

The power output performance of energy harvesting devices (EHDs) dictates device suitability for most applications, and the higher the power harvested, the wider the application potential can be. Geometric parameters of EHDs and the electric loads connected to them can significantly influence the power output performance in an increased or decreased manner. Recently Zhu et al. [1-2], using a commercial finite element software, developed a coupled piezoelectric-circuit finite element model (CPCFEM), to model a vibration-based piezoelectric EHD that is directly connected to a load resistor. The CPC-FEM was used to predict the generated output power of the EHD with different load resistor values while simultaneously calculating the effect of the load resistor value on the displacement amplitude of the tip of the cantilever. Furthermore, Zhu and Worthington [3] used the CPC-FEM to perform a design study of the Piezoelectric EHD (PEHD), which is a cantilever sandwich structure with a seismic mass attached to the tip, for gaining an understanding of the influence of the geometric parameters on the electric output performance of the device. The authors also established a simplified analytical model of the PEHD [4] that considers the effects of both the beam and mass geometric parameters; the simplified analytical model was used to optimize the design of the PEHD to obtain maximum power output with a volume of around $1 \mathrm{~cm}^{3}$. As mentioned above, the first study of this paper authors was on the effects of the resistive load value on the electric power output of the device and the displacement amplitude of the tip of the cantilever [1-2]; the second was on the effect of the geometric parameters on the power output of the device [3], and the third was for optimizing the dimensions for the generation of maximum power output with a volume of $1 \mathrm{~cm}^{3}$ [4]. This letter further presents our experimental study on the electric output performance of the optimized PEHD when it is directly connected to a variety of different resistive load values. The main motivation of this letter is, based on experimental results, to gain an understanding of how the resistive load connected with a vibration-based PEHD affects its power/voltage output performance and to demonstrate the power output of our optimized PEHD.

\section{CONFIGURATION OF PEHD}

Figure 1 shows a photo of the prototyped PEHD used in the experimental study, which is based on the optimised configuration studied in [3-4]. Table 1 lists the material properties and structural parameters of the PEHD. It is a piezoelectric bimorph cantilever with a seismic mass symmetrically attached at the tip. The beam is a sandwich structure with a central brass substrate layer and two piezoelectric material layers; one bonded to the top and the other to the bottom of the central brass layer. The surfaces (both top and bottom) of each piezoelectric layer are covered by a thin nickel electrode, except for those portions of the layers that lie between the masses. The electrodes were removed from these areas using $\mathrm{FeCL}_{3}$, ferric chloride solution, in order to reduce the piezoelectric 


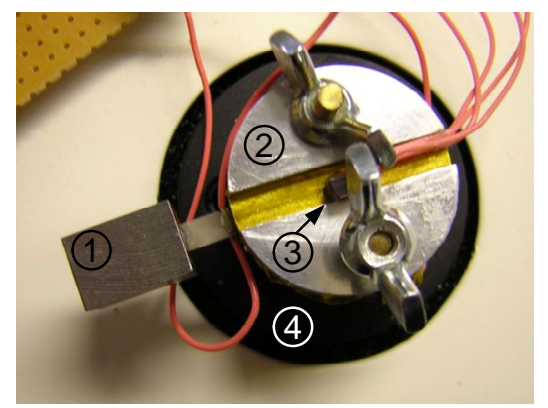

Figure 1 Photo of the prototyped PEHD. Note: the dimensions shown in the figure 1 are all in $\mathrm{mm}$ and the sandwich structure detail is not shown in the schematic; the thickness of $0.66 \mathrm{~mm}$ includes the brass central layer thickness of $0.102 \mathrm{~mm}$ and the two piezoelectric layer thicknesses, each of $0.278 \mathrm{~mm}$. The photo shows a plan view of the PEHD clamped in the aluminum holder, where: (1): the PEHD, (2): the aluminum holder, (3): the accelerometer, and (4): the shaker armature. The total volume of the PEHD is around $1 \mathrm{~cm}^{3}$.

Table 1 Material properties and structural parameters of the prototyped PEHD

\begin{tabular}{|c|c|}
\hline \multicolumn{2}{|l|}{ Substrate material: brass } \\
\hline Young's modulus (GPa) & 110 \\
\hline Poisson's ratio $\mu_{\mathrm{s}}$ & 0.23 \\
\hline Density $\left(\mathrm{kg} / \mathrm{m}^{3}\right)$ & 2330 \\
\hline $\begin{array}{l}\text { Length* } \times \text { width } \times \text { thickness }(\mathrm{mm}) \\
* \text { The total length of mass and piezoelectric layer }\end{array}$ & $18^{*} \times 3.1 \times 0.102$ \\
\hline \multicolumn{2}{|c|}{$\begin{array}{l}\text { Piezoelectric material: PSI-5H4E (Piezo Systems Inc, } \\
\text { Massachusetts). }\end{array}$} \\
\hline \multicolumn{2}{|c|}{\begin{tabular}{l|l} 
Young's modulus $(\mathrm{GPa})$ &
\end{tabular}} \\
\hline $\mathrm{E}_{11}$ & 62 \\
\hline $\mathrm{E}_{33}$ & 50 \\
\hline Poission's ratio & 0.3 \\
\hline \multicolumn{2}{|l|}{ Elastic constants:(GPa) } \\
\hline $\mathrm{C}_{11}$ & 110.8 \\
\hline $\mathrm{C}_{12}$ & 49.8 \\
\hline $\mathrm{C}_{13}$ & 49.8 \\
\hline $\mathrm{C}_{33}$ & 110.8 \\
\hline $\mathrm{C}_{44}$ & 30.5 \\
\hline Density $\rho_{\mathrm{p}}\left(\mathrm{kg} / \mathrm{m}^{3}\right)$ & 7800 \\
\hline \multicolumn{2}{|l|}{ Piezoelectric constants $\left(\times 10^{-12} \mathrm{~m} / \mathrm{volt}\right)$} \\
\hline $\mathrm{d}_{33}$ & 650 \\
\hline $\mathrm{d}_{31}$ & -320 \\
\hline \multicolumn{2}{|l|}{ Coupling coefficients } \\
\hline $\mathrm{k}_{33}$ & 0.75 \\
\hline $\mathrm{k}_{31}$ & 0.44 \\
\hline Relative dielectric constant $\quad \varepsilon_{33}$ & 3800 \\
\hline Mechanical quality factor $\mathrm{Q}$ & 32 \\
\hline Length $\times$ width $\times$ thickness $(\mathrm{mm})$ & $6 \times 3.1 \times 0.278$ \\
\hline \multicolumn{2}{|c|}{$\begin{array}{l}\text { Seismic mass material: Tungsten alloy (M \& I Materials } \\
\text { Ltd/Wolfmet, Manchester, UK) }\end{array}$} \\
\hline Young's modulus (GPa) & 400 \\
\hline Poisson's ratio $\mu_{\mathrm{s}}$ & 0.28 \\
\hline Density $\left(\mathrm{kg} / \mathrm{m}^{3}\right)$ & 18100 \\
\hline Length $\times$ width $\times$ height $(\mathrm{mm})$ & $12 \times 8.2 \times 9.4$ \\
\hline
\end{tabular}

capacitance of the device, and so increase the output voltage and power, since these areas don't generate the electric charge and reduce the output voltage for the studied case as the charge generated is limited. The piezoelectric layers are poled in the same direction, so that when the PEHD is subjected to acceleration, charge of the same polarity appears on the outer electrodes of the device. Thus the device is wired so that the piezoelectric layers are connected in parallel: the outside electrodes are connected together to make one electrical output terminal, and the centre layer constitutes the other electrical output terminal. The volume of the PEHD is around $1 \mathrm{~cm}^{3}$.

\section{EXPERIMENTAL SET-UP AND TESTING APPROACHES}

Figure 2 shows a photo and schematic of the experimental setup. The system is based on National Instruments hardware and software. The laptop PC interfaces via USB to a CompactDAQ chassis (National Instruments, Texas) that contains two modules: a 9263 analogue output module that connects to a PA30E power amplifier (Data Physics/Gearing \& Watson, California) that drives a V20 shaker (Data Physics), and a 9229 analogue input module that connects to the PEHD output via a load-board.
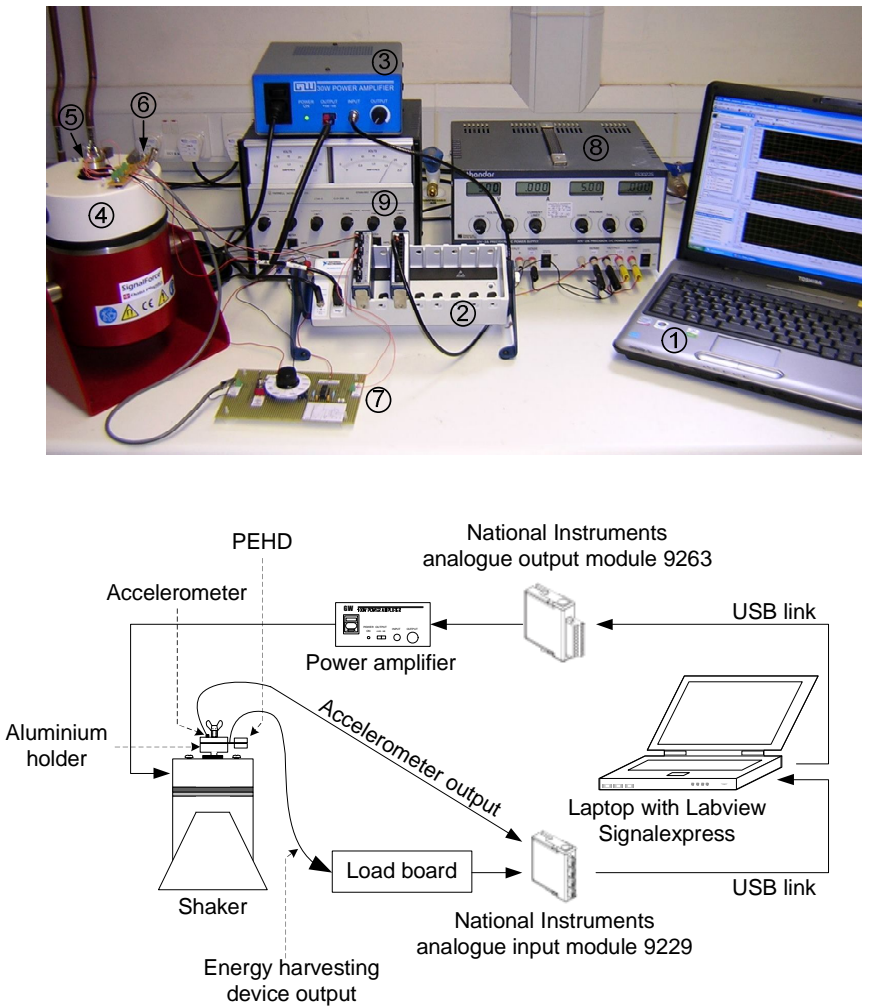

Figure 2 Photo and schematic of the experimental test setup. In the photo: (1) Laptop PC with Labview SignalExpress, (2) National Instruments CompactDAQ chassis with 9229 and 9263 modules, (3) Shaker power amplifier, (4) Electromagnetic shaker, (5) Aluminum holder with PEHD and accelerometer, (6) Circuit board for accelerometer supporting components, (7) Load-board, (8) Power supply for accelerometer, (9) Power supply for load-board. 
The PEHD is clamped into an aluminium holder that is mounted on top of the shaker. Also on the aluminium holder is an ADXL103 accelerometer (Analog Devices, Massachusetts) which is used to show the input acceleration applied to the PEHD, thus placement of the accelerometer was chosen to be as close as possible to the fixed end of the beam. The accelerometer has a sensitivity of $1 \mathrm{~V} / \mathrm{g}$. The output of the PEHD is connected to a custom built load-board. The load-board is essential for taking the measurements as it serves two purposes: firstly, it allows different resistive load values (from $25 \mathrm{k} \Omega$ to $550 \mathrm{k} \Omega$ in $25 \mathrm{k} \Omega$ steps) to be connected to the PEHD; secondly, through use of an instrumentation amplifier it isolates the $1 \mathrm{M} \Omega$ input impedance of the analogue input module from the PEHD output, presenting instead a $10 \mathrm{M} \Omega$ input impedance to the PEHD. The output of the instrumentation amplifier is connected to an input channel of the analogue input module. The output of the accelerometer is connected to another input channel.

To test the device, Labview SignalExpress software (National Instruments) was first used to generate an electric signal to drive the shaker at a given frequency (chosen arbitrarily at $110 \mathrm{~Hz}$ ) while the amplitude of excitation was manually adjusted using the control on the power amplifier until the chosen acceleration value of $+/$ $0.23 \mathrm{~g}$, which is based on [6], representing an ambient vibration from environment, and recorded on the accelerometer output. SignalExpress was then used to perform a series of frequency sweeps from $70 \mathrm{~Hz}$ to $110 \mathrm{~Hz}$; each sweep was performed with a different resistive load connected to the PEHD. The responses from the accelerometer and PEHD were recorded at each frequency integer within this frequency range, resulting in two collections of data for each restive load applied: acceleration applied to the PEHD versus frequency, and voltage output of the PEHD versus frequency. Since the data obtained from the accelerometer showed that the acceleration applied to the PEHD did not maintain the exactly required amplitude of $+/-0.23 \mathrm{~g}$ over the frequency range (possibly caused by the shaker's dynamic response), the data from the accelerometer was used to rescale the output voltage of the PEHD, so that any deviation from the required $+/-0.23 \mathrm{~g}$ that occurred as the frequency changed was accounted for. The purpose of rescaling the output of the PEHD was to ensure that the voltage data obtained was representative of a constant acceleration amplitude value over the frequency range of interest. The power output of the PEHD was then calculated from (1).

$$
P=\frac{V^{2}}{2 R}
$$

where $P$ is the output power of the PEHD (equivalent to the power dissipated by the load resistor), $R$ is the load resistor value, and $V$ is the output voltage amplitude of the PEHD, measured across the load resistor.

\section{EXPERIMENTAL RESULTS AND DISCUSSION}

Figure 3 shows the measured output voltages of the PEHD as a function of frequency and with various resistive loads, ranging from $25 \mathrm{k} \Omega$ to $550 \mathrm{k} \Omega$. From the figure, it can be observed that the maximum output voltage (occurring at resonance) initially increases with the increase in resistive load value, and then starts to approach a level. For example, the difference between the voltages obtained at resonance with $R=25 \mathrm{k} \Omega$ and $R=50 \mathrm{k} \Omega$ is $2.01 \mathrm{~V}$, whereas the difference between the voltages obtained at resonance with $R=525 \mathrm{k} \Omega$ and $R=550 \mathrm{k} \Omega$ is only $340 \mathrm{mV}$. Furthermore, it can also be observed that the resonant frequency of the device gradually shifts to a higher frequency as the resistive load increases. These results agree with our previous simulation results obtained by using the CPC-FEM proposed in [1-2].

Figure 3 shows that the output voltage of the PEHD increases with an increase in the resistive load value. However, the output power of the PEHD doesn't increase with the value of the resistive load because the power is determined by Equation (1). Based on Figure 3 and Equation (1), the power dissipated by the resistor as a function of frequency versus various electric resistances can be easily calculated. Figure 4 shows the voltage measured across the load resistor and power dissipated by it versus load resistance values, where the data were extracted at the frequency of the peak of the curves. A maximum output power of $370 \mu \mathrm{W}$ was generated into a resistive load of $325 \mathrm{k} \Omega$ at the operating frequency of $87 \mathrm{~Hz}$ and under an acceleration of $0.23 \mathrm{~g}$. This power value is comparable to those presented in [5-6], in which the power outputs reported were $365 \mu \mathrm{W}$ [5] and $335 \mu \mathrm{W}$ [6] for a volume of around $1 \mathrm{~cm}^{3}$ and under the same excitation acceleration. This is a very encouraging power figure that gives the prospect of being able to power a wider range of applications than is currently possible.

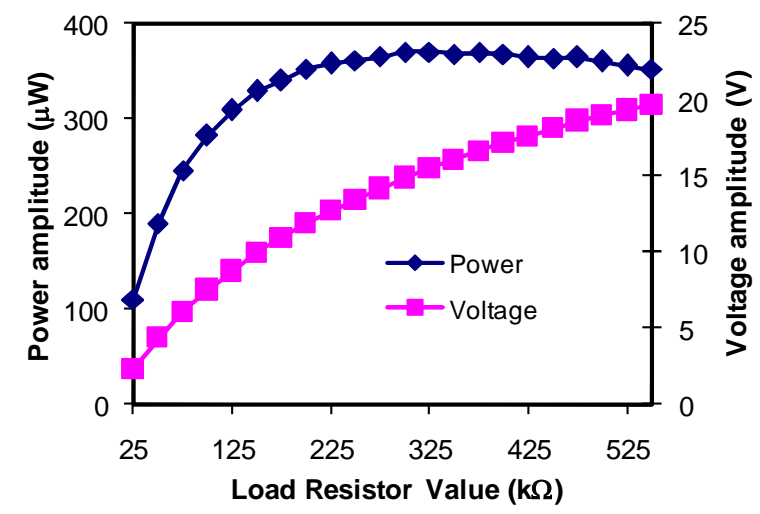

Figure 4 Voltage measured across and power dissipated by the load resistor versus resistance value under their resonant frequency and an acceleration of $0.23 \mathrm{~g}$ 


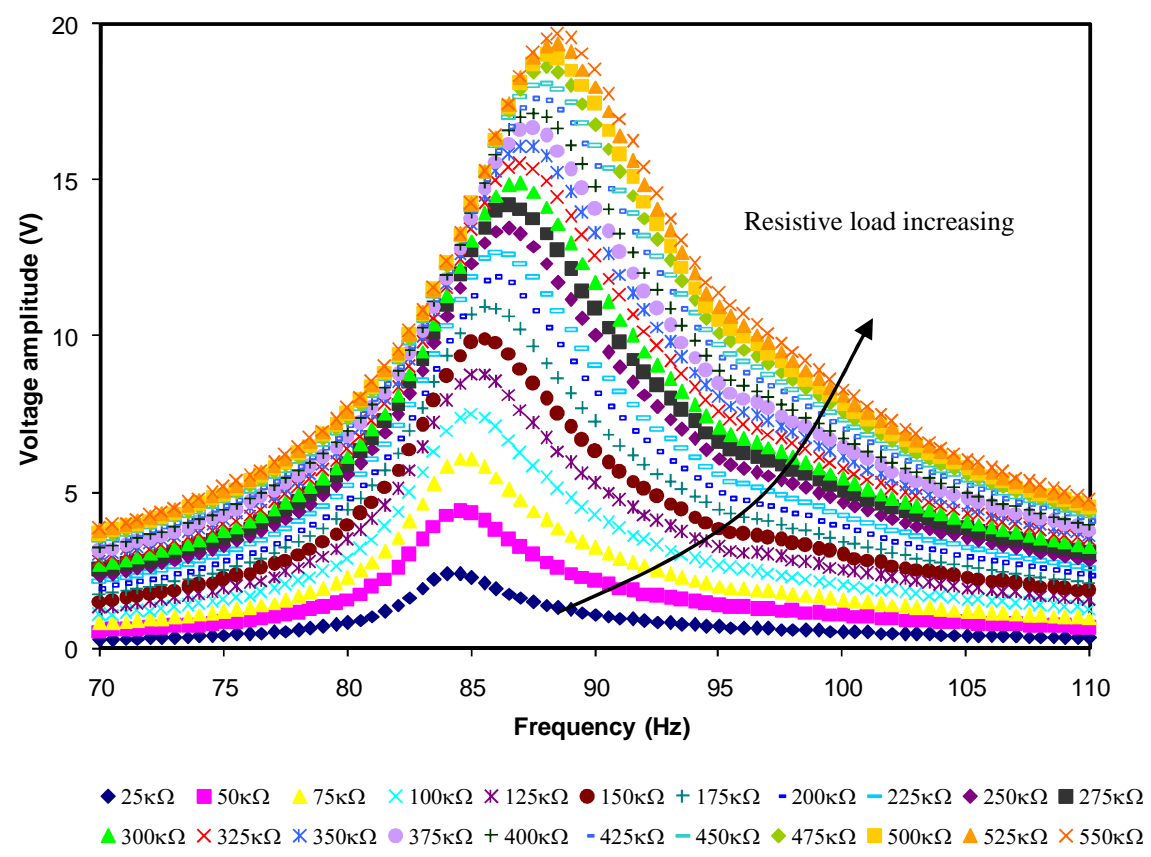

Figure 3 Output voltage of the PEHD as a function of frequency with various resistive load values and under an acceleration of $0.23 \mathrm{~g}$

\section{CONCLUSIONS}

In conclusion, the electric output performance of a vibration-based PEHD directly connected to a resistive load has been investigated experimentally based on our optimized PEHD, which is a cantilever with a sandwich structure and seismic mass attached to the tip. A maximum output power of $370 \mu \mathrm{W}$ at 15.5 volts into a $325 \mathrm{k} \Omega$ resistive load was achieved at the operating frequency of $87 \mathrm{~Hz}$ and under an acceleration of $0.23 \mathrm{~g}$. . Quite remarkably, this power is a very encouraging power figure that gives the prospect of being able to power a wider range of applications than is currently possible in wireless sensor network. In addition, Our previous findings on the effect of the resistive load value on the voltage and power generated by the PEHD, particularly in terms of the shift in resonant frequency of the device, has been validated.

\section{ACKNOWLEDGMENTS}

The authors gratefully acknowledge the support from IMRC (the Cranfield Innovative Manufacturing Research Centre) via EPSRC (Engineering and Physics Science of Research Council in the UK) entitled "Design and Manufacturing of a Novel EHDs for Self Powered Sensors and ICT Applications" (IMRC-137) and EPSRC Platform Grant entitled "Nanoscale Multifuctinal Ferroic Material and Devices" (EP/D506638/1).

\section{REFERENCES}

[1] M. Zhu, E. Worthington and J. Njuguna, "Analyses of power output of piezoelectric energy harvesting devices directly connected to a load resistor using a coupled piezoelectric-circuit finite element method", Ultrasonics, Ferroelectr. Freq. Contr., IEEE Trans, vol. 56, pp. 1309-1318, 2009.

[2] M. Zhu, \& E. Worthington, \& J. Njuguna, "Coupled piezoelectriccircuit FEA to study influence of resistive load on power output of piezoelectric energy devices", Proc. of SPIE, Smart Sensors, Actuators and MEMS IV, Vol. 7362, 736202-1-12, 2009.

[3] M. Zhu, \& E. Worthington, "Design study of piezoelectric energy harvesting devices for higher electrical power output using a coupled piezoelectric-circuit finite element method", IEEE Transactions on Ultrasonics Ferroelectrics and Frequency Control, in review.

[4] E. Worthington and M. Zhu, "Optimisation design of piezoelectric energy harvesting devices based on a simplified analytical model and experimental study for generating higher electric power for wireless sensor network", will be submitted, 2009.

[5] P. D. Mitcheson, E. M. Yeatman, G. K. Rao, A. S. Holmes, and T.C. Green, "Energy harvesting from Human and machine motion for wireless electronic devices", Proceeding of the IEEE, vol.96, No.9, pp. 1457-1486, September, 2008.

[6] S. Roundy, P. K. Wright and J. M. Rabaey, Energy Scavenging for Wireless Sensor Networks: With Special Focus on Vibrations. Springer, 2004.

[7] S. Roundy, P. K. Wright and J. Rabaey, "A study of low level vibrations as a power source for wireless sensor nodes," Comput. Commun., vol. 26, pp. 1131-1144, 2003.

[8] S. P. Beeby, M. J. Tudor and N. M. White, "Energy harvesting vibration sources for microsystems applications", Measur. Sci. Technol., vol. 17, pp. 175-, 2006. 